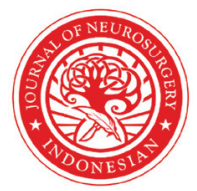

Indonesian Journal of Neurosurgery
'Department of Neurosurgery, Faculty of Medicine, Universitas Padjadjaran, Dr. Hasan Sadikin Hospital, Bandung, West Java, Indonesia;

\footnotetext{
*Corresponding author: Agung Budi Sutiono; Department of Neurosurgery, Faculty of Medicine, Universitas Padjadjaran, Dr. Hasan Sadikin Hospital, West Java, Indonesia;

agungbudis@gmail.com
}

Received: 2021-07-20

Accepted: 2021-10-26

Published: 2021-12-04

\section{Characteristics and clinical findings of traumatic brain injury patients in single referral hospital dr. Hasan Sadikin hospital, Bandung, West Java, Indonesia}

\author{
Muhammad Zafrullah Arifin ${ }^{1}$, Agung Budi Sutiono ${ }^{1 *}$, Rendy Febrian Badri ${ }^{1}$
}

\title{
ABSTRACT
}

Introduction: Traumatic brain injury (TBI) is the leading cause of mortality and morbidity in children and young adults globally. Knowledge of TBI characteristics holds importance on the treatment improvement of and scientific progression. Thus, this study aimed to evaluate the characteristics of TBI in Hasan Sadikin Hospital.

Methods: Analysis of data obtained from a retrospective review of medical records and from a systematic database pertaining to diagnostic criteria of TBI treated in the Department of Neurosurgery at Dr. Hasan Sadikin Hospital, Bandung, Indonesia from January $1^{\text {st }} 2012$ to December $31^{\text {st }} 2018$.

Results: This study included 10,234 cases over the described time period. Men had a higher prevalence of TBI (7,539 patients or $73.7 \%$ ) compared to women (2,695 patients or $26.7 \%)$. The majority of the cases were mild TBI (68.3\%). The most common skull fracture was linear fracture (68.6\%), while the majority of skull base fracture was anterior skull base fracture (66.7\%). The majority of intracranial lesions were cerebral contusion (26.4\%). Intracranial lesions were commonly observed in patients with moderate or severe than mild TBI.

Conclusion: The incidence of accompanying intracranial lesions and skull fracture were commonly observed in patients with moderate or severe TBI than patients with mild TBI.

Keywords: alcohol intoxication, intracranial lesions, skull base fracture, skull fracture, traumatic brain injury. Cite This Article: Arifin, M.Z., Sutiono, A.B., Badri, R.F. 2021. Characteristics and clinical findings of traumatic brain injury patients in single referral hospital dr. Hasan Sadikin hospital, Bandung, West Java, Indonesia. Indonesian Journal of Neurosurgery 4(3): 112-115. D0I: 10.15562/ijn.v4i3.183

\section{INTRODUCTION}

Traumatic brain injury (TBI) is a disruption in the normal function of the brain that can be caused by a blow, bump or jolt to the head, the head suddenly and violently hitting an object, or when an object pierces the skull and enters the brain tissue..$^{1-3}$ TBI is a global health issue and a leading cause of death and morbidity in children and young adults worldwide. ${ }^{3}$ It has been estimated that more than 50 million people experience TBI each year and at least half of the world's population experiences $\geq$ 1 TBI during their lifetime. The majority of the patients $(80 \%)$ who arrived at the hospital were classified as mild TBI, $10 \%$ are moderate TBI, and the remaining $10 \%$ was severe TBI. ${ }^{3}$

TBI includes open and closed TBI. Intracranial lesions were commonly found in patients with skull fractures. The presence of skull fractures allows for a larger subdural or epidural hematoma than injury without fracture. Fractures are considered important in indicating the location and severity of the TBI. ${ }^{4}$ TBI is most likely to result in death or disability than other types of injuries. ${ }^{3-5}$

Glasgow Coma Scale (GCS) is a reliable tool to assess the prognosis in patients with TBI. The degree of severity of TBI is also classified based on the GCS score. GCS score can also reflect intracranial pathology. The presence of alcohol intoxication in patients with TBI might increase the morbidity and mortality rates from TBI. The higher blood level of alcohol is proportional to the decrease of GCS. ${ }^{2,3,5}$

Until now, there is a lack of literature describing patients with TBI in Indonesia, therefore the authors aimed to describe characteristics of patients with TBI in Hasan Sadikin Hospital.

\section{METHODS}

The study had been approved by the Ethical Committee of Hasan Sadikin Hospital. The subjects were patients with TBI who receive treatment at the Department of Neurosurgery of Dr. Hasan Sadikin Hospital during the period of January 2012 - December 2018. All patients who presented with spontaneous intracranial bleeding were excluded.

This was a descriptive study using archival data from the medical record. The sample selection in this study was a total sampling technique by including all patients with TBI patients who receive treatment at the Department of Neurosurgery of Dr. Hasan Sadikin Hospital Bandung in the period of January 2012 - December 2018.

Data analysis was carried out using the SPSS for Windows version 20 program. Characteristics of patients with TBI were 
Table 1. Distribution of research subjects based on variables.

\begin{tabular}{lcc} 
Characteristics & $\mathbf{N}$ & $\%$ \\
\hline Gender & 10,234 & 73.7 \\
Male & 7,539 & 26.3 \\
Female & 2,695 & \\
Severity of TBI & 10,234 & 68 \\
Mild TBI & 6,989 & 24 \\
Moderate TBI & 2,445 & 8 \\
Severe TBI & 800 & 30.46 \\
Bone fracture & 3,118 & 68.6 \\
Linear fracture & 2,140 & \\
& & 12.8 \\
Open depressed & 399 & 7.5 \\
Closed fracture & 233 & 6.3 \\
Diastatic fracture & 197 & 4.8 \\
Avulsion fracture & 149 & 12.08 \\
Skull base fracture & 1,237 & 66.7 \\
Anterior & 825 & 29.2 \\
Middle & 361 & 4.1 \\
Anterior and middle & 51 & 48.23 \\
Intracranial lesions & 4,936 & 26.4 \\
Cerebral contusion & 1,301 & 24.2 \\
Epidural hematoma & 1.195 & 17.5 \\
Subdural hematoma & 865 & 14.5 \\
Intracerebral hematoma & 718 & 2.4 \\
Intraventricular hemorrhage & 120 & 14.9 \\
Subarachnoid hemorrhage & 737 & \\
& & \\
\hline & & \\
& & \\
& &
\end{tabular}

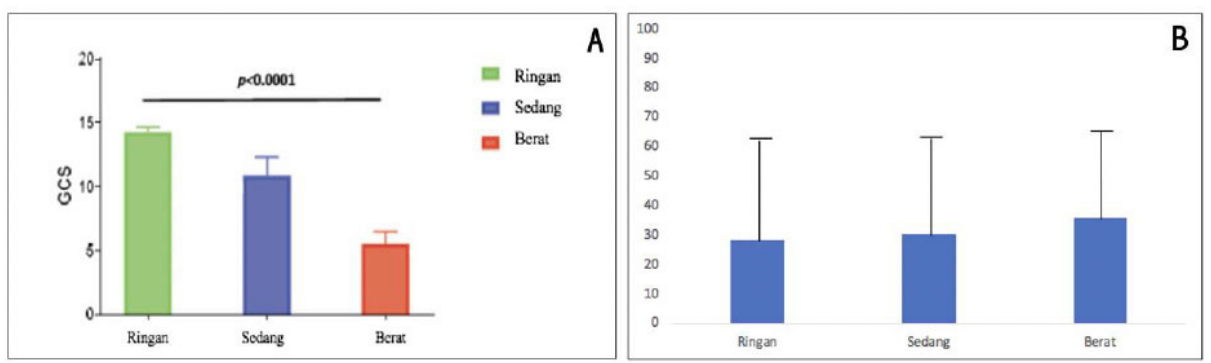

Figure 1. A. The mean GCS of patients with TBI; B. The mean age of patients with TBI.

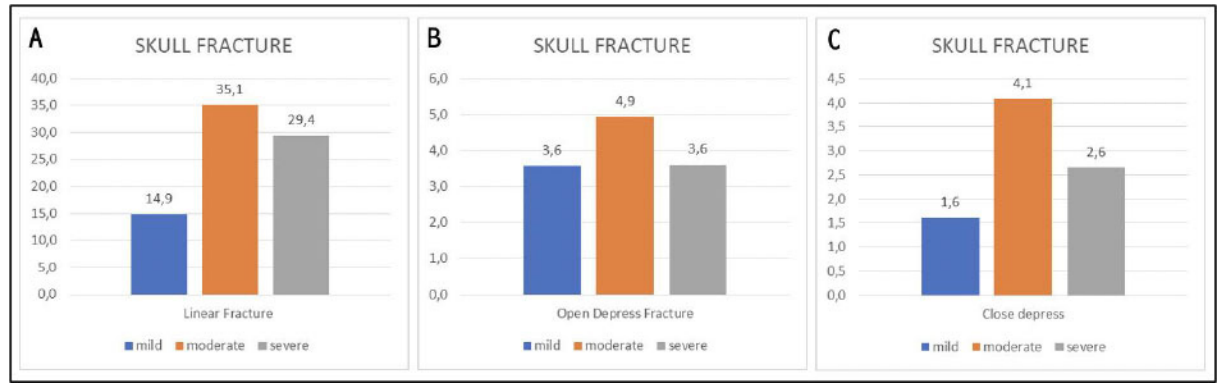

Figure 2. A. The distribution of TBI patients with linear skull fractures; B. Distribution of TBI patients with open depressed fractures; C. Distribution of TBI patients with closed depressed fractures. presented in numbers and percentages.

\section{RESULTS}

The total number of subjects in this study was 10,234 patients with TBI. Table 1 showed that out of 10,234 research subjects, 7,539 patients (73.7\%) were males and 2,695 (26.3\%) were females. As can be seen in Fig. 1A, 6,989 (68\%) patients were diagnosed with mild TBI with a mean GCS of 14.74, 2445 (24\%) patients were diagnosed with moderate TBI and a mean GCS of 11.02 , and $800(8 \%)$ patients with severe TBI and mean GCS of 5.38 ( $\mathrm{p}<$ 0.0001).

A total of 3,118 patients had skull fractures, including 2,140 (68.6\%) linear fractures, 399 (12.8\%) open depressed fractures, $233(7.5 \%)$ closed depressed fractures, 197 (6.3\%) diastatic fractures and $149(4.8 \%)$ avulsion fractures. Total 1,237 patients experienced skull base fracture, of which 825 (66.7\%) patients had anterior skull base fracture, 361 (29.2\%) patients were diagnosed with middle skull base fracture, and $51(4.1 \%)$ patients had anterior and middle skull base fracture.

By computed tomography (CT) scan of the head, intracranial lesions were found in 4,936 patients, including 1,301 (26.4\%) patients with cerebral contusions, 1,195 (24.2\%) patients with epidural hematoma $(\mathrm{EDH}), \quad 865(17.5 \%)$ patients had a subdural hematoma, 718 (14.5\%) patients had an intracerebral hematoma (ICH), 120 patients had intraventricular hemorrhage (IVH), and 737 (14.9\%) patients had subarachnoid hemorrhage (SAH).

The mean age of patients with a mild TBI was 28.43 years, the mean age of patients with a moderate TBI was 30.27 years, and the mean age of patients with a severe TBI was 35.88 years (Fig. 1B). Patients with alcohol intoxication often presented with a lower GCS (13.09 \pm 2.029), than patients without alcohol intoxication (13.42 \pm 3.142$)$. Nevertheless, this difference did not affect the severity of TBI.

Linear skull fracture was more likely to be diagnosed in patients with moderate and severe TBI than with mild TBI (Fig. 2A). Open depressed skull fracture was more likely to be diagnosed in patients with moderate TBI than severe or mild TBI (Fig. 2B). Closed depressed skull 


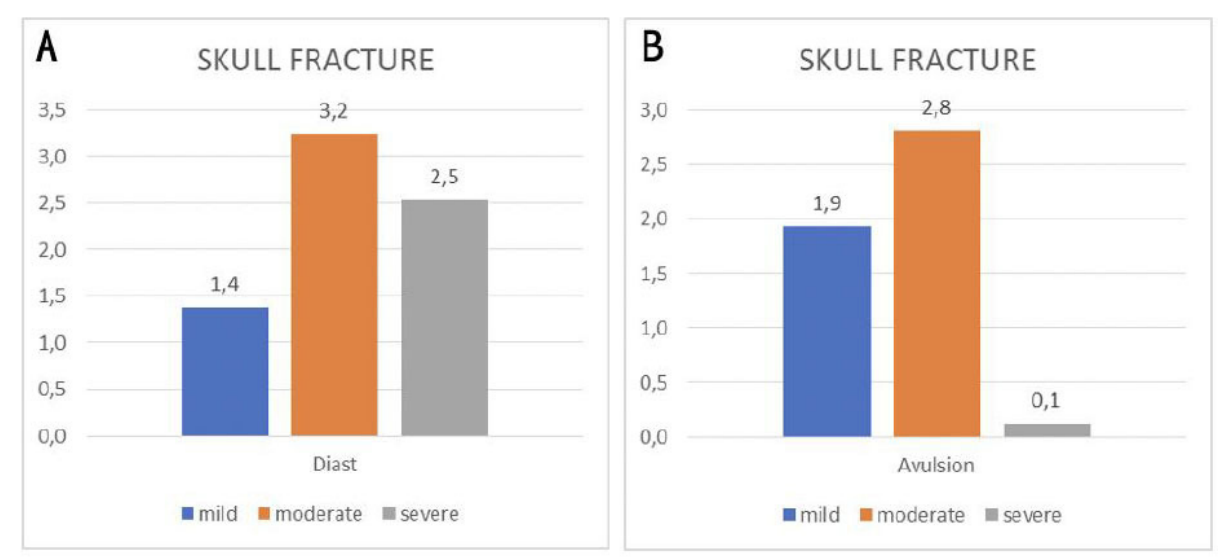

Figure 3. A. Distribution of TBI severity in patients with diastatic fractures; B. Distribution of TBI severity in patients with avulsion fractures.
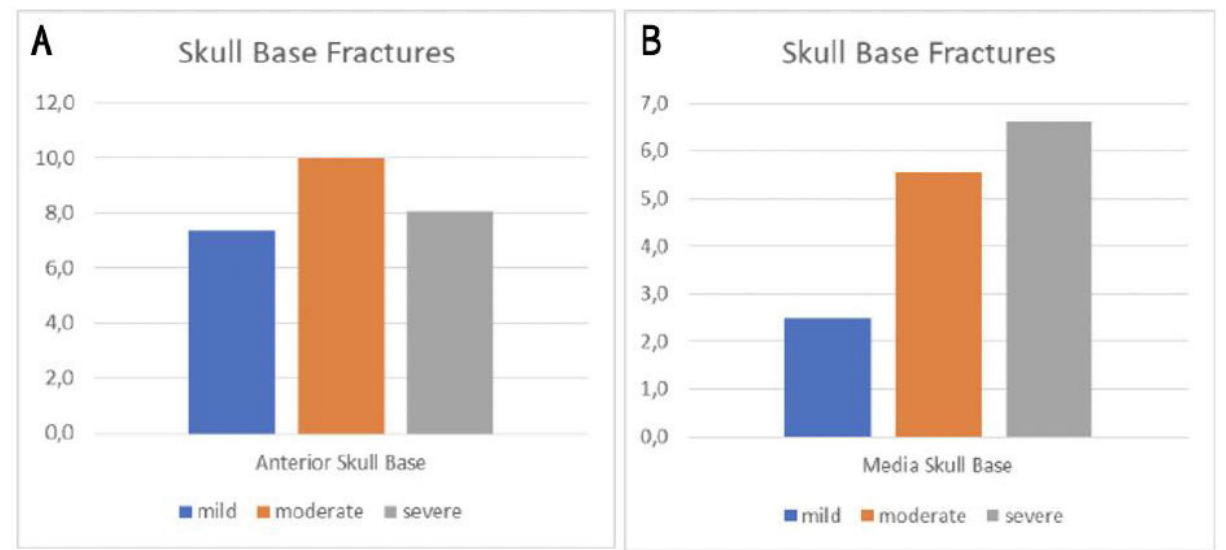

Figure 4. A. Distribution of TBI patients with anterior skull base fracture. B. Distribution of TBI patients with middle skull base fracture.

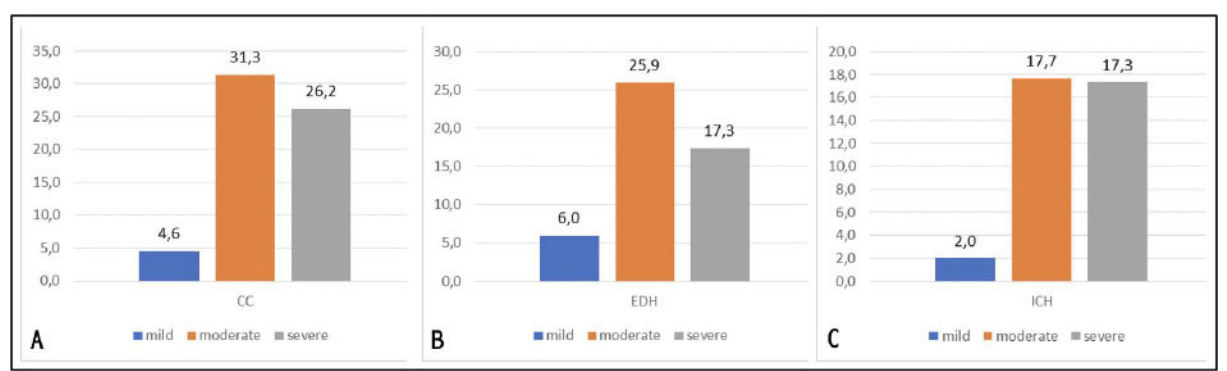

Figure 5. A. Distribution of TBI patients with a contusion; B. Distribution of TBI patients with epidural hematoma; C. Distribution of TBI patients with subdural hematoma.

fracture was more likely to be diagnosed in patients with moderate TBI than patients with mild TBI or severe TBI (Fig. $2 \mathrm{C})$. The diastatic fracture was commonly found in patients with moderate and severe TBI than with mild TBI (Fig. 3A). Avulsion fracture was commonly found in patients with a moderate and mild TBI bleeding, and subarachnoid hemorrhage were more likely to be diagnosed with a moderate and severe TBI than mild TBI (Fig. 5A, 5B, 5C, 6A, 6B, and 6C).

\section{DISCUSSION}

This study sample was 10,234 research subjects who had met the inclusion and exclusion criteria. Based on demographic characteristics, the percentage of men with TBI $(73.7 \%)$ was higher than that of women (26.3\%). TBI is more common in men because men are usually more physically active and have behaviors that tend to be at risk of injury. ${ }^{6,7}$ Mild TBI was the most common form of TBI at Dr. Hasan Sadikin Hospital in 2012 2018 (68.3\%). The finding reflects the epidemiological facts that mild TBI is the majority case of TBI. ${ }^{8}$

Linear skull fracture was the most common skull fracture in this study. A similar result was reported by Lee et al. that the most common skull fracture was the linear type (64.6\%), followed by mixed fractures $(20.6 \%)$ and diastatic fractures (7.6\%). ${ }^{9,10}$ The most common intracranial lesions found in this study were cerebral contusions (26.4\%). A similar result was also reported in the literature that cerebral contusion was commonly observed in patients with TBI (40.8\%) in 2013. ${ }^{11}$

In this study, the mean of GCS in the patients with alcohol intoxication was lower than in the patients without alcohol intoxication. A previous study conducted on 108,929 accidents involving alcohol showed that alcohol intoxication did not significantly reduce GCS in patients with TBI at a young age. After stratifying by the severity of brain injury, the reduction in GCS due to alcohol intoxication was slight. Therefore, it is not advisable to determine diagnostic or therapeutic measures by looking at blood alcohol levels. ${ }^{12,13}$

This study indicated that patients with moderate and severe TBI were more frequently diagnosed with skull fractures than patients with mild TBI. Hard impact on a flat surface causes the linear fracture, and if the fracture line is on the temporal bone, the possibility of an epidural hematoma is increased. The presence of skull fractures increases the likelihood of intracranial lesions, therefore head CTscan examination is needed to rule out 


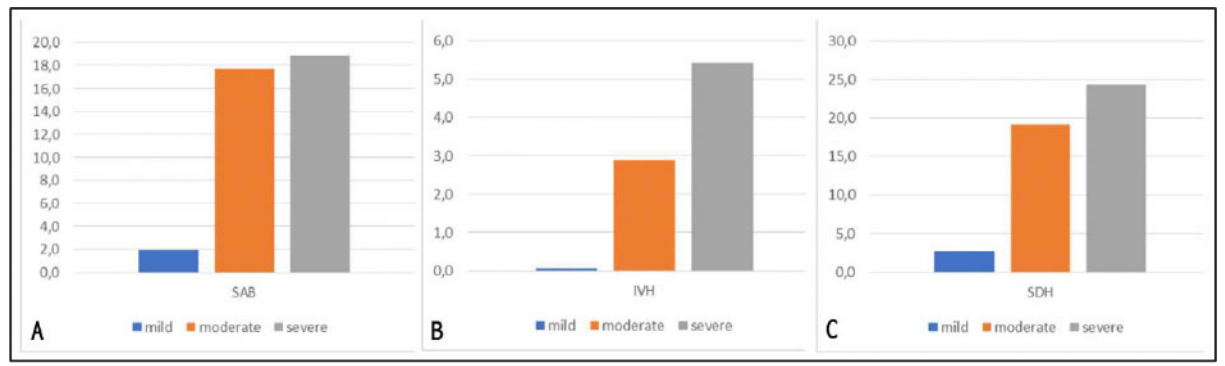

Figure 6. A. Distribution of TBI patients with intracerebral hematoma; B. Distribution of TBI patients with intraventricular hemorrhage; C. Distribution of TBI patients with subarachnoid hemorrhage.

intracranial bleeding/lesions. ${ }^{14-16}$

In this study, intracranial lesions were more likely to be observed in patients with moderate or severe TBI. Intracranial lesions (hemorrhage) might become a space-occupying lesion and lead to brain herniation and hemodynamic disturbances, resulting in ischemia or brain infarction. Traumatic intracranial hemorrhage is associated with cortical and subcortical brain damage, which can interfere with brain function. ${ }^{17}$

Based on our knowledge, this study is involving the largest number of TBI patients in Indonesia. Thus, the data generated through this study has the potential to have clinical importance. This study has several limitations, such as not revealing confounding variables in the patient's medical record. The confounding variables that can influence the results of this study were intracranial diseases and other extracranial diseases. Examples of this confounding variable are aneurysms, hypertension, diabetes mellitus, and heart disease. It is likely to affect the severity of TBI. Furthermore, this study also did not consider the time interval between the onset of TBI and the admission of the patient to the hospital for treatment. Future studies that consider those confounding variables will provide a better picture of the characteristics of patients with TBI.

\section{CONCLUSION}

The incidence of accompanying intracranial lesions and skull fracture were commonly observed in patients with moderate or severe TBI than patients with mild TBI.

\section{CONFLICT OF INTEREST}

The authors declare no conflict of interest.

\section{FUNDING}

None.

\section{AUTHOR CONTRIBUTION}

The authors contributed equally in preparing this manuscript.

\section{REFERENCES}

1. Faried A, Bachani AM, Sendjaja AN, Hung YW, Arifin MZ. Characteristics of moderate and severe traumatic brain injury of motorcycle crashes in Bandung, Indonesia. World Neurosurg. 2017; 100: 195 - 200. https://doi. org/10.1016/j.wneu.2016.12.133.

2. Faried A, Halim D, Widjaya IA, Badri RF, Sulaiman SF, Arifin MZ. Correlation between the skull base fracture and the incidence of intracranial hemorrhage in patients with traumatic brain injury. Chin J Traumatol. 2019; 22(5): 286 - 289. https://doi.org/10.1016/j. cjtee.2019.05.006.

3. Ghajar J. Traumatic brain injury. Lancet. 2000; 356(9233): 923 - 929. https://doi.org/10.1016/ S0140-6736(00)02689-1.

4. Corrigan JD, Selassie AW, Orman JAL. The epidemiology of traumatic brain injury. J Head Trauma Rehabil. 2010; 25(2): 72 - 80. https:// doi.org/10.1097/HTR.0b013e3181ccc8b4.

5. McIntyre A, Mehta S, Aubut J, Dijkers M, Teasell RW. Mortality among older adults after traumatic brain injury: a meta-analysis. Brain Inj. 2013; 27(1): 31 - 40. https://doi.org/10.3109 102699052.2012 .700086$.

6. Tagliaferri F, Compagnone C, Korsic M, Servadei F, Kraus J. A systematic review of brain injury epidemiology in Europe. Acta Neurochir (Wien). 2006; 148(3): 255 - 268; discussion 268. https://doi.org/10.1007/s00701-005-0651-y.

7. Faried A, Satriawan FC, Arifin MZ. Feasibility of online traumatic brain injury prognostic corticosteroids randomisation after significant head injury (CRASH) model as a predictor of mortality. World Neurosurg. 2018; 116: e239 - 245. https://doi.org/10.1016/j. wneu.2018.04.180.

8. Langlois J, Rutland-Brown W, Wald MM. The epidemiology and impact of traumatic brain injury: A brief overview. J Head Trauma Rehabil. 2006; 21(5): 375 - 378. https://doi. org/10.1097/00001199-200609000-00001.

9. Roozenbeek B, Maas AIR, Menon DK. Changing patterns in the epidemiology of traumatic brain injury. Nat Rev Neurol. 2013; 9(4): 231 - 236. https://doi.org/10.1038/nrneurol.2013.22.

10. Umerani MS, Abbas A, Sharif S. Traumatic brain injuries: Experience from a tertiary care centre in Pakistan. Turk Neurosurg. 2014; 24(1): 19 - 24. https://doi.org/10.5137/1019-5149. JTN.7080-12.1.

11. Mokolane NS, Minne C, Dehnavi A. Prevalence and pattern of basal skull fracture in head injury patients in an academic hospital. SA J Radiol. 2019; 23(1): 1677. https://doi.org/10.4102/sajt. v23i1.1677.

12. Rosyidi RM, Priyanto B, Laraswati NKP, Islam AA, Hatta M, Bukhari A, et al. Characteristics and clinical outcome of traumatic brain injury in Lombok, Indonesia. Interdiscpl Neurosurg. 2019; 18: 100470. https://doi.org/10.1016/j. inat.2019.04.015.

13. Dewan MC, Rattani A, Gupta S, Baticulon RE, Hung Y-C, Punchak M, et al. Estimating the global incidence of traumatic brain injury. J Neurosurg. 2018; 1 - 18. https://doi. org/10.3171/2017.10.JNS17352.

14. Shandro JR, Rivara FP, Wang J, Jurkovich GJ, Nathens AB, MacKenzie EJ. Alcohol and risk of mortality in patients with traumatic brain injury. J Trauma. 2009; 66(6): 1584 - 1590. https://doi.org/10.1097/TA.0b013e318182af96.

15. Zvejniece L, Stelfa G, Vavers E, Kupats E, Kuka J, Svalbe B, et al. Skull fractures induce neuroinflammation and worsen outcomes after closed head injury in mice. I Neurotrauma. 2020; 37(2): 295 - 304. https://doi.org/10.1089/ neu.2019.6524.

16. Jokar A, Ahmadi K, Salehi T, Sharif-Alhoseini M, Rahimi-Movaghar V. The effect of tranexamic acid in traumatic brain injury: A randomized controlled trial. Chin J Traumatol. 2017; 20(1): 49 - 51. https://doi.org/10.1016/j. cjtee.2016.02.005.

17. Satardey RS, Balasubramaniam S, Pandya JS, Mahey RC. Analysis of factors influencing outcome of depressed fracture of skull. Asian J Neurosurg. 2018; 13(2): 341 - 347. https://doi. org/10.4103/ajns.AJNS_117_16.

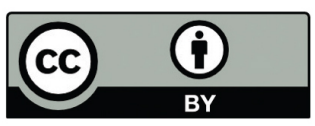

This work is licensed under a Creative Commons Attribution 